\title{
Online intercultural exchange: policy, pedagogy, practice
}

\author{
JOSÉ MARCELO FREITAS DE LUNA \\ Universidade do Vale do Itajaí, Itajaí, SC, Brazil \\ RODRIGO SCHAEFER \\ Universidade Federal de Santa Catarina, Florianópolis, SC, Brazil \\ O'Dowd, Robert; LewIS, Tim. Online \\ Intercultural Exchange: Policy, \\ Pedagogy, Practice. New York: \\ Routledge, 2016. 308p.
}

The book Online Intercultural Exchange: Policy, Pedagogy, Practice, edited by Robert O'Dowd and Tim Lewis, touches upon issues concerning telecollaboration and consists of five parts subdivided in 17 chapters. In the first chapter, Introduction to Online Intercultural Exchange and this Volume, Lewis and O'Dowd begin by conceptualizing telecollaboration, based on a review of several studies derived from research in the area. Although the tone of the authors is veritably optimistic, they responsibly present data that do not point to the entry or to the successful use of Online Intercultural Exchange (OIE) in institutions around the world.

The second chapter, Online Intercultural Exchange and Foreign Language Learning: A Systematic Review, also written by O'Dowd and Lewis, aims to punctually show how OIE contributes to the learning of foreign languages in university education. The required answer is achieved by means of a descriptive map that includes 54 articles published in scientific journals and book chapters. These are investigations that explore the importance of off-line study and reflection, as well as of development and feedback when it comes to tasks.

In chapter 3, Internationalization and the Role of Online Intercultural Exchange, Wit presents sections marked by the redefinition of internationalization concepts such as internationalization at home and internationalization of the curriculum. What the author contends concerns all researchers and managers of academic internationalization: this process should extend to all students.

In chapter 4, Online Intercultural Exchange in Europe: State of the Art and Implications for the Future, Guth calls into question that telecollaboration should 
occur less in a top-down perspective than in a more personal scope. Thus, the need to sustain online telecollaborative practice associated with the need for internationalization in higher education is confirmed.

In the fifth chapter, Internationalization, The Bologna Process and Online Intercultural Exchange: Seeking Common Ground, Wilson focuses on enabling and inhibitory influences of socio-political realities, exploiting two case studies. Although both cases are well sustained, readers may find it difficult to grasp the objective of the chapter, that is, to reveal how international policies directed by Bologna enable and hinder aspects of telecollaborative interaction.

In the sixth chapter, An Overview of Online Intercultural Exchange in the Australian Context, Tudini discusses how teachers of a university of foreign language in Australia apply telecollaboration. According to him, the achievement of extracurricular activities implies autonomy of students, who should be provided with a level of linguistic competence that allows them to partake in telecollaborative interactions without the help of others.

The development process of Intercultural Communicative Competence (ICC) and Symbolic Competence (SyC) is explored in chapter 7 by Mueller-Hartmann and Kurek: Designing Tasks for University Online Intercultural Exchange. Analyses of the study indicated that when instructions for tasks are clearly communicated, collaboration between students is more intense and engaged compared to when the task provides merely procedural steps without clarity of purpose.

In chapter 8, Facilitated Dialogue in Online Intercultural Exchange, Helm presents a dialogic model of online intercultural exchange. The author analyzes data from online interactions of a group of students from the United States and the Middle East. Likewise, he describes The Soliya Connect Program (SCP), a telecollaborative project integrated in the curriculum of several universities worldwide. One of Helm's contributions in this chapter is her call to responsibility of foreign language teachers in helping students whose perspectives are different to discuss different views negotiated in interactions.

The following chapter, Combining Classroom-based Learning and Online Intercultural Exchange in Blended Learning Courses, by Nissen, addresses the issue of how the combination of face-to-face and distant-teaching modes of teaching in a context of hybrid learning occurs. Chapter 9 is proven relevant by considering OIE the main learning mode. Firstly, because designing and preparing a course with distant partners is a complex and lengthy process. Secondly, once the online component is regarded as an effective means of achieving learning objectives, it appears to gain a central role in the designed courses.

Chapter 10, Please Remove Your Avatar From My Personal Space: Competences of the Telecollaboratively Efficient Person, by Dooly, intends to show a set of descriptors - and skills - that make up a Telecollaboratively Efficient Person (TEP). Precisely, Dooly states that such descriptors can be used by both teachers and students who aim at identifying the different attitudes, skills, knowledge, and behaviors that together form a specific competence: the telecollaborative.

A framework for the recognition of learning efforts with view to the certification of OIE practitioners' engagement and task design is proposed in chapter 
11: A New Approach to Assessing Online Intercultural Exchanges: Soft Certification of Participant Engagement, by Hauck and Mackinnon. The authors promptly suggest a framework in which it is conceivable, from different categories of OIE tasks explained, to illustrate the moment of the journey or learning process when the use of badge typology can potentially be used to positively motivate learners, since they would acknowledge their efforts in their own learning.

The chapter The Clavier Network, by Mckinnon, describes the project The Clavier Network, intended for a broad exchange between the University of Warwick (United Kingdom) and Clermont-Ferrand (France). The overall objective was to create a shared space for participants for both formal and informal interactions. The author states that this project gave Clavier a fluidity of identity and agency that is not common in online teaching contexts.

Leone and Telles are the authors of The Teletandem Network, a descriptive and explanatory text about Teletandem Brasil. As conclusion, they highlight the expectation of keeping the project focused on the pedagogy grounded on technology and research in the area of communication. They also depict a plan to make Teletandem available in Brazilian high schools.

Chapter 14, The Cultural Exchange Programme, by Furstenberg, relates to a hybrid learning environment created by Fusrtenberg at the Massachusetts Institute of Technology (MIT), in the United States. For Furstenberg, welcoming the announced importance of internationalization of the curriculum propelled by the current information technology and seen in the early days of project, makes it clear that the prefix "inter" in the words/terms inter-culturality and inter-net cause the motivation and interest necessary to engender intercultural encounters between his and other students from dissimilar cultures.

Byram addresses The Cultnet Intercultural Citizenship Project in chapter 15. The objective of the project is to verify whether and how education for citizenship can become the focus of the teaching and learning of languages through subprojects. Byram reiterates that subprojects should develop intercultural citizenship. As the chapter includes few pages, it lacks a more detailed description of the project, and the reader who is unaware of Cultnet may come across doubts about its implementation.

In the subsequent chapter, The COIL Network: Online Intercultural Exchange in the SUNY Network of Universities, by Rubin, Collaborative Online International Learning (COIL) is introduced. Not necessarily a project, COIL's mission is to develop online and hybrid courses with the incorporation of international and intercultural dimensions. The author mentions some problems faced by the initiative such as the implementation of these practices in more traditional universities, the lack of infrastructure resources and the need for integration of courses to disciplines' content.

Chapter 17 is a glance at the future of OIE, written by Robert O'Dowd under the title Learning From the Past and Looking to the Future of Online Intercultural Exchange. It corresponds to each criticism that this activity has received over the past twenty years. In line with the proposal of the book, stated in the first chapter, O'Dowd concludes the present edition by agreeing with the relevance and opportunity towards criticism, stating that these should all be considered, as they 
tend to improve OIE as far as its applicability in higher education and, in particular, foreign language teaching is concerned.

For its well-founded and explored parts - theory and practice - , the book in question stands out in both fields, OIE and internationalization, as a recent and valuable contribution. Researchers, teachers, and practitioners can benefit from an enlightening text that is fundamental for education in general and language teaching in particular.

\section{REFERENCE}

O’Dowd, R.; Lewis, T. Online Intercultural Exchange: Policy, Pedagogy, Practice. New York: Routledge, 2016.308p.

\section{ABOUT THE AUTORS}

José Marcelo Freitas de Luna is a Ph.D. in linguistics from Universidade de São Paulo (USP). Professor at Universidade do Vale do Itajaí (Univali). E-mail:mluna@univali.br

Rodrigo Schaefera is doctorate in English from Universidade Federal de Santa Catarina (UFSC). E-mail: rodrigoschaefer2@gmail.com

Received on June 30, 2016 Approved on December 16, 2016 